\title{
First-Year Medical Student Experiences Adjusting to the Immediate Aftermath of COVID-19
}

\author{
Mark D. Slivkoff ${ }^{1}$ (D) $\cdot$ Catherine Johnson $^{2} \cdot$ Sean Tackett ${ }^{3}$ \\ Accepted: 10 January 2021 / Published online: 22 January 2021 \\ (C) International Association of Medical Science Educators 2021
}

\begin{abstract}
Problem The COVID-19 pandemic required rapid changes to medical curricula, forcing emergent transition to purely remote learning. At Idaho College of Osteopathic Medicine (ICOM), all in-person sessions were suspended on March 16, 2020. One course affected included the first-year, 4-week Respiratory System course which began on March 9.

Methods On the final day of the course, students were sent surveys which assessed how they adjusted academically and personally to the campus shutdown.

Results The response rate was 137/159 (86\%). Students' learning adjustments took into account changes to spaces and daily routine, their cohabitants, need for accountability, new learning resources, and anxiety. Most students were concerned about public health, the economy, and health of family and loved ones; fewer were concerned about their professional futures, restrictions on personal freedoms, and own health. Most students adjusted personally by connecting more with family, entertainment and sleep, and studying less. While a large majority of students made changes to connecting with friends and physical activity, students did not adjust uniformly.
\end{abstract}

Keywords COVID-19 $\cdot$ Online education $\cdot$ Social distancing

\section{Problem}

The COVID-19 pandemic required rapid changes to medical school curricula in the USA [1] and worldwide [2-4], forcing students and faculty to engage in "emergency remote teaching" [5].

Understandably, much attention has been paid to COVID19's impact on clinical learning. In the USA, on March 17, medical school accrediting authorities strongly recommended suspending student learning in patient care settings to prevent

Lessons Learned During a successful emergent transition to remote learning, students' academic and personal adjustments were highly individualized. Supporting students in a crisis requires appreciating all aspects of their human experiences.

Mark D. Slivkoff

mslivkoff@idahocom.org

1 Idaho College of Osteopathic Medicine, 1401 E Central Dr, Meridian, ID 83642, USA

2 Osmosis.org, New Haven, CT, USA

3 Division of General Internal Medicine, Johns Hopkins Bayview Medical Center, Baltimore, MD, USA students from becoming ill and using the limited supply of personal protective equipment [6, 7]. As of May 2020, few schools had resumed students' clinical learning, and away electives remained discouraged [8]. The points of view of clinical learners have been represented in a variety of publications [9-13].

Perhaps less attention has been paid to medical students early in their training, who are typically not immersed in clinical settings. These students are likely to face unique challenges if an abrupt and major change occurs because many are still transitioning. Early medical students are often beginning their professional identity formation, seeking to understand what it will mean for them individually to "think, act, and feel like a physician" through a gradual process of socialization that can be disorienting and stressful [14]. They must also adapt to a challenging curriculum and position themselves for success in a highly competitive national system characterized by pressure to stand out with extracurricular achievements and high scores on standardized exams [15].

In addition to potentially disrupting learning, COVID-19 disrupted students' lives as the same social distancing requirements that made medical education fully remote impacted students' daily activities. A report from a Chinese medical 
school shortly after COVID-19 took hold in China indicated approximately a quarter of its students had symptoms of anxiety [16] (although how these levels related to previous levels was not reported) [17]. Psychological distress among adults in the USA in general was higher when measured in April 2020 compared to 2018 levels [18]. Medical students are unlikely to be immune to the same adverse non-academic influences that COVID-19 may have on other adults, although how such factors impacted this group has not been characterized.

In this article, we describe the emergent mid-course transition that took place for first-year medical students at one US medical school due to COVID-19 and an evaluation of students' adjustments to both new methods of learning and new ways of living due to social distancing restrictions.

\section{Methods}

\section{Subjects and Setting}

The Respiratory System course for first-year medical students at Idaho College of Osteopathic Medicine (ICOM) was scheduled to take place from March 9, 2020, to April 10,2020 . The course is part of ICOM's 2-year preclinical curriculum, and one of 11 organ systems-based courses in which foundational concepts in anatomy, biochemistry, cell biology, physiology, pharmacology, microbiology, immunology, and pathology are integrated in an interleaved fashion with clinical content. The course runs concurrently with Clinical Small Groups and Osteopathic Principles and Practice courses. The course was designed to have approximately $15 \mathrm{~h}$ of in-person lectures and $2 \mathrm{~h}$ of in-person discussions each week with the curriculum supplemented by digital resources. ICOM announced on March 15 that all inperson sessions would be suspended beginning on March 16, the beginning of the second week of the course.

ICOM is located in southwest Idaho, approximately 10 miles from Boise. The first confirmed case of COVID-19 in Idaho was March 13 and Idaho's first COVID-19 deaths were March 26. The Idaho governor encouraged stricter social distancing on March 18 and issued a stay-at-home order on March 25 that remained in place through April 30.

Students in the Respiratory System course were the second cohort to enroll at ICOM, whose inaugural class matriculated in Fall 2018. Among students in the course, Idaho residents made up $17 \%$, with the remainder coming from 36 other states. The cohort had an average age of 23 , with $62 \%$ men, $17 \%$ married, and an ethnic breakdown of $75 \%$ white, 14\% Asian, 4\% Hispanic, and 6\% other. Students, faculty, staff, and administrators shared one common building, which lent itself to a learning environment in which students had built close relationships with each other and many who work in the building.
At ICOM, all large-group sessions are recorded live, and recordings (via Panopto software) are made immediately available to the students. Since most sessions are not mandatory, before the COVID-19 pandemic a majority of students opted to view recordings in lieu of attending sessions in person.

\section{Respiratory System Course Adjustments}

After the emergent announcement to cease live sessions and transition to fully remote learning on March 15, classes were held as scheduled beginning on March 16 and continued without a change to the overall course organization, including the order of lectures and course-wide and session-specific learning objectives. All session materials remained available to the students via the learning management system (LMS). Faculty were given the option to either present to an empty lecture hall while being recorded or record their lectures as screencasts using the software of their choice. All faculty participated in this process and recordings were made available via Panopto for asynchronous viewing among the session materials in the LMS. Optional student discussion sessions were carried out using video conferencing software (Cisco WebEx). Students continued to have access to several other digital resources.

Adjustments were made to the scheduled assessments. The midterm examination, which was scheduled approximately a week after the announcement of the closure, was canceled. To compensate, the number of multiple-choice questions (MCQs) on the remaining quiz and the final examination was increased by a factor of 1.5. The final examination assessed learning against the same learning objectives but was converted from a 2-h proctored examination to a weeklong open-book assessment. The current grading policy, based on letter grades, remained unchanged.

Students were constantly updated and supported emotionally during campus closure. Most teaching faculty expressed words of encouragement during their session recordings. In lieu of sending emails, the course director updated students mainly via video (i.e., vlogs), and many students reciprocated by sending their videos to the course director.

\section{Course Evaluation}

All students were sent electronic surveys on April 10, after the deadline for submission of their final exam; data collection closed on April 15. While students in the Respiratory System course were concurrently enrolled in Clinical Small Groups and Osteopathic Principles and Practice courses, our evaluation did not focus on those courses, and those courses used their standard course evaluation survey. 
Open-ended items on the survey asked: (1) "How did the changes to the course brought about by COVID-19 influence your learning?", (2) "What adjustments did you make to deal with changes to the course?", (3) "Please describe, in general, what is weighing on you most as a result of the COVID-19 pandemic.", and (4) "What strategies have you used to cope with social distancing and other changes brought about by COVID-19?" Two quantitative items with 5-point Likert-type response options asked students how concerned they were about 7 issues related to COVID-19 and to what extent they had changed 11 different activities as a result of COVID-19. All survey response data were deidentified prior to analysis. Open-ended items were independently reviewed and coded for themes by all authors. Illustrative quotes were selected for themes and edited as required to ensure quotes could not be linked to individual students. Descriptive statistics were used to analyze quantitative items. This study was deemed exempt by the Boise State University Institutional Review Board (SB-IRB Notification of Exemption-998-SB20-090).

\section{Discussion}

All students submitted their assessments on time and passed the course. A total of 137/159 (86\%) responded to the end-ofcourse evaluation.

\section{Influence of COVID-19 on Students' Learning}

Themes from student responses related to changes in the course were as follows: (1) access to preferred learning spaces, (2) revised daily schedule and routine, (3) need for accountability and self-regulation, (4) new learning methods and resources, (5) consideration and responsibility for cohabitants, and (6) anxiety from personal and academic uncertainty related to COVID-19's impact. Illustrative quotes for each theme are in Table 1.

Generally, the influence of the pandemic on learning was most pronounced for those who experienced the most change in their routine.

I am a student that consistently attends lectures, so the quarantine definitely altered my educational routine. Initially, I found it a little harder to motivate myself to study when I [was] sitting at home all day with two [others] around, but once I established a routine of waking up at 6:30 AM (like I used to ... when getting ready for each day) and sitting at the kitchen table and going through the day's lectures, I got into a groove. In short, while the initial transition to distance learning was tough for me, I quickly adjusted.
However, some students did not require much of an adjustment:

I had been watching all the lectures online anyway before the virus, so it really didn't affect me ... all that much.

Others felt they were unable to make a full transition:

I struggled with the changes. I had a hard time focusing and my anxiety increased fourfold... I am still trying to figure out how to adjust.

Some were frankly upbeat about the changes they made:

I was surprised how easy it was to adjust..... I got into a routine quickly so being able to focus at home and study at home wasn't too hard. In my apartment, the living room has plenty of natural light so I could study. In addition, I bought some plants to help make things more soothing. I also actually started working out more, and losing weight again finally cause I began working out every day. My routine was study in the morning with light breakfast, then work out and make dinner, then study again after. I just feel very efficient.

\section{Student Concerns Related to COVID-19}

A majority of students expressed "a lot" or "extreme" concern about the toll COVID-19 would take on public health (64\%) or the economy $(61 \%)$, the health of family and loved ones (61\%), and not knowing when it would end (59\%), while fewer were concerned about their academic/professional futures $(34 \%)$, restrictions on personal freedoms $(20 \%)$, and their own health (17\%) (Fig. 1).

Responses to open-ended prompts largely aligned with these categories and shed light on how issues were weighing on students. Many reported multiple issues concerning them:

I am worried about the health of my family and friends. I am also worried about not learning effectively during this time and how that will affect my board scores next year. I am also worried that I am not doing enough to help the community and people who are sick.

\section{Some Were Most Concerned by Issues at the Societal or System Levels}

Honestly, the thing that I am most worried about is the economy. I have a lot of questions that I just can't find an 
Table 1 Themes and illustrative quotes for responses from 137 students on how their learning was influenced by changes to a first-year respiratory system course as a result of COVID-19

Theme Quotes

Access to preferred learning spaces

Revised daily schedule and routine

Need for accountability and self-regulation

New learning methods and resources

Consideration and responsibility for cohabitants

Anxiety from personal and academic uncertainty related to COVID-19's impact
COVID-19 has influenced my learning by limiting my normal habits of study. For example, I mainly studied at local coffee shops or in the school library, but due to these places being closed down, I have been forced to study at home, which is difficult for me.

I'm definitely not use to studying at home. We live in a tiny 1-bedroom apartment with a dog and several tvs and an oven to bake it....it's a distracting environment. I've just never been able to concentrate at home because there's always something to clean or fix or do, so a change in study atmosphere is the biggest thing.

After a week of slacking, I knew I had to make a change. I found that getting up early in the mornings, like I would have done if we were still at the campus, really helped. I made myself get up, each day, drink coffee, get dressed, and then I would sit at my desk and begin. I tried to keep the routine.

Honestly, at first, it was kind of intimidating just because I felt like I was having to do everything alone. However, after the first week, I knew that if I kept a schedule and woke up at the same time every day I could make it happen.

The changes were extremely hard for me. I am one of the 40 students who goes to class every day and it holds me accountable. Without this, it is hard to get up every day and get the motivation to watch the lectures.

At first, I did not do much different. But I noticed my resolve was slipping away. So the last couple weeks I had a study buddy and in the morning we would tell each other the top 3 things we needed to get done by noon. Then check in at noon. Then another 3 things and checked in in the evening. Having told someone and then having to tell them if I had indeed completed what I set out to do helped me stay motivated. We are going to continue this for the neuro block.

I am relying more heavily on my outside resources given that asking questions of professors is more difficult during this time.

I thought that the changes in the course were not only extremely fair, but helped me with my learning. It took away the stress that was present at first, and it made learning remotely actually kind of fun. I was incredibly grateful for the changes that were made to the course.

I like at home so I had to adjust to studying and doing schoolwork with my husband and entire family around me. I had to let everyone know that I need to study and to not bother me.

I spent more time parenting in an effort to give my wife a break. I took my son on long walks every afternoon and reviewed stuff while we walked. I talked to my son as if I was teaching him the concepts. That forced me to think through things and solidified it in my mind

I struggled daily to find time to keep up with material. I had to share my small apartment with a wife and child who wanted to spend as much time with me as possible

In the beginning, it was hard to focus on studying for long periods of time because I just wanted to keep checking the news every 30 minutes.

For the first couple weeks I had to take care of my family and assure I had enough food and supplies in case things went sour. I take care of my parents and they live in another state which made things much more stressful for me. They're also at a very vulnerable age where risk of death was a high possibility if they contracted the disease. During this time it was very difficult to concentrate on school work. answer to. What is our plan for the second wave for this virus? Are we planning on social distancing again when it likely returns in the fall? Can our economy even handle that? If we don't social distance again, was this all a waste? Long story short, I am just concerned about the decisions that our society will make in the future. I know it is out of my hands, but these are definitely the things that are weighing on me the most right now.

Generally, I'm disappointed at the US response to the pandemic. We were slow to act at all and the approach we have taken after we acted doesn't seem to be helping people who need it most financially. I'm concerned about how we, as a country, come out of this pandemic and rebuild our healthcare system, our public health system, and the economy

Others focused more on personal issues:

The main issue is my concern for immunocompromised family members in [another state] and not being able to travel home because it is a high-risk area.

With a [baby] at home, the idea of my wife or I getting sick was of great concern, how do we take care of her if we are both sick? 
Fig. 1 Responses from 137 firstyear medical students to "How concerned are you about each of the following at this time?" in a course evaluation survey administered April 10, 2020

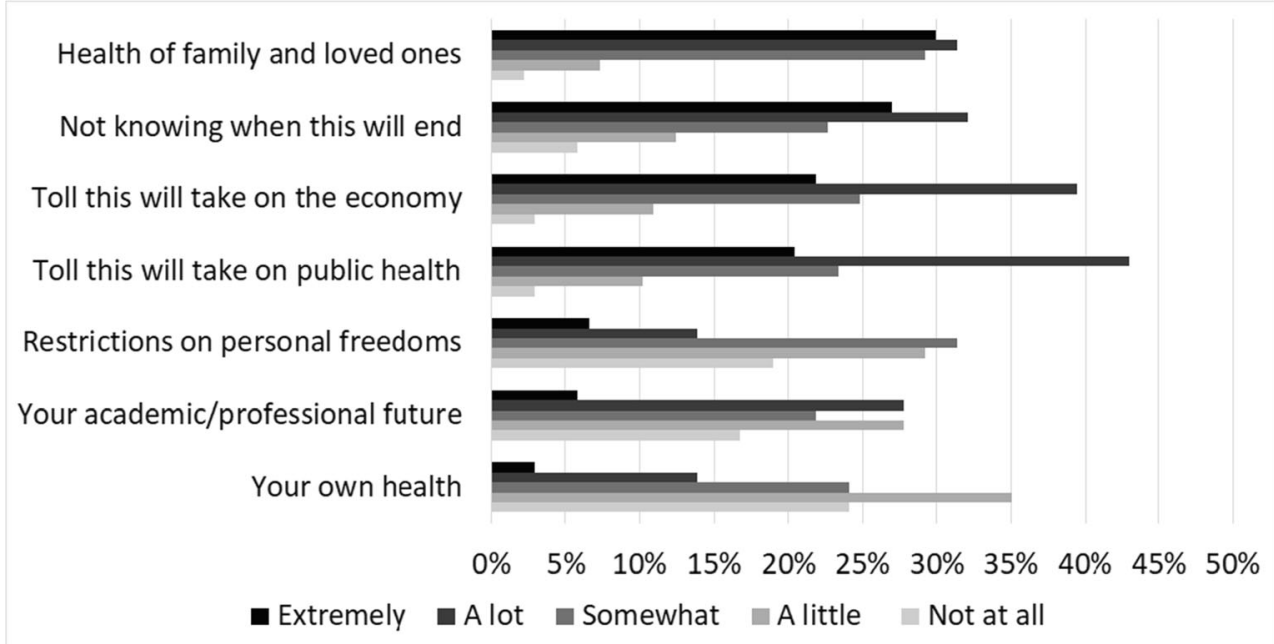

Uncertainty surrounding one's academic and professional future was illustrated by quotes such as:

Personally, I am wondering/concerned about when we are going to be able to go back to school. I understand that there are much bigger fish to fry with this pandemic going on but losing out on the majority of the resources ICOM has to offer is a big concern of mine.

I feel worried that distance learning will affect my performance on the boards in a negative manner, but more importantly, I fear that my ability as a future physician could be compromised.

Others' comments were directed more at the general uncertainty affecting all of us:

I would say the uncertainty is weighing on me the most, just not knowing a timeline for when life will go back to the 'new' normal

Perhaps reflecting the unspoken concerns of many, one student simply wrote:

I just do not want to get sick

\section{Changes Students Made in Response to COVID-19}

The majority of students reported connecting more with family $(72 \%)$, more entertainment $(66 \%)$ and sleep $(60 \%)$, less studying for medical school (54\%), and no change in meditation or other mindfulness practices (52\%). While a large majority of students made changes to connecting with friends (79\%), physical activity/exercise (84\%), and spending time outdoors (90\%), students did not adjust uniformly, with percentages of more vs less for each activity being, $45 \%$ vs $34 \%, 35 \%$ vs $49 \%$, and $46 \%$ vs $43 \%$, respectively (Fig. 2).

Responses to open-ended prompts indicated that some students felt that minimal changes were necessary:

I am a reserved individual socially already and I tend to stay home, so this has not required any additional changes on my part.

Some traveled to be physically present with others:

I drove back home to be with family. We support and motivate each other in these difficult times, and it has had an enormous impact on my mental health. I am also able to frequently video call my friends and classmates, and we still keep tabs on one another and make each other laugh.

Others were physically present in "social pods" [19].

We are group isolating with another family because his wife watches my kids. We didn't have a whole lot of other friends to begin with so... yeah, not much has changed.

My wife and I selected her sister, husband, and my nephew to isolate with in addition to a fellow classmate and his family. This may not be exact social distancing but we all limit contact with others outside of our group and this has worked well so far

Many reported changing multiple activities while social distancing:

I've been exercising more at home. I've been trying to take advantage of some of the upsides of being home all the time, like having more time to cook, play piano, 
Fig. 2 Responses from 137 firstyear medical students to "As a result of changes due to COVID19 , how has each of the following changed?" in a course evaluation survey administered on April 10, 2020

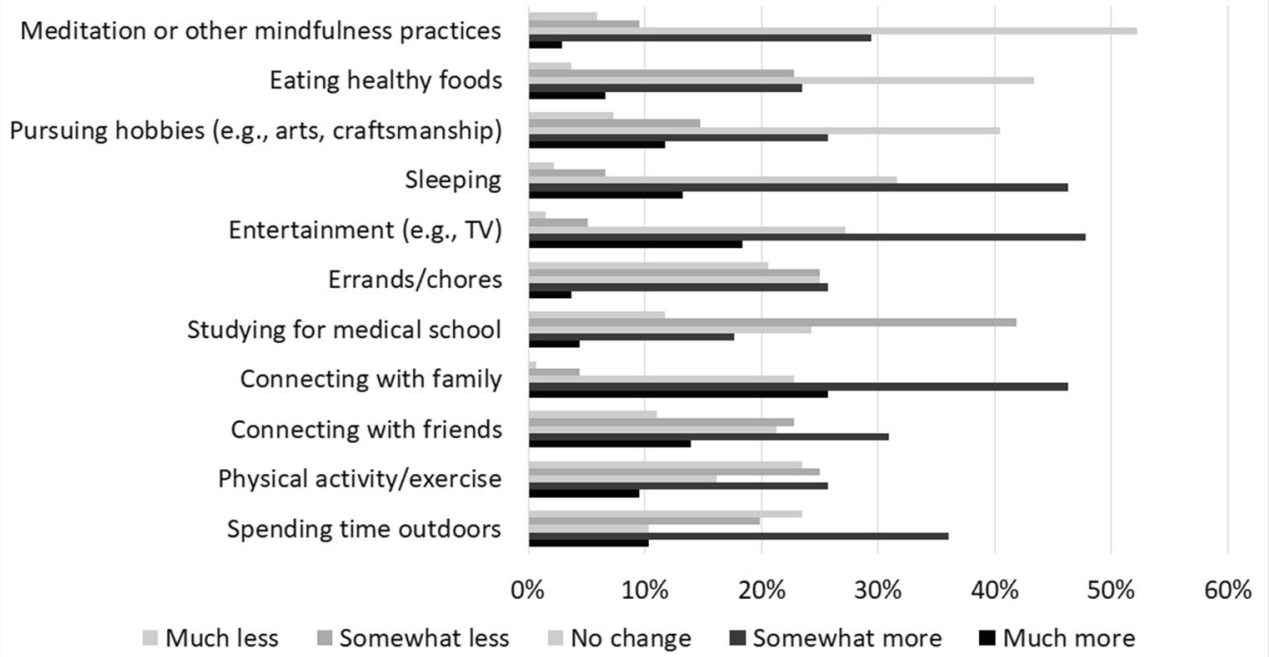

read, spend time with my cat, etc. I've also been making a point to stay in touch with people. One of the things I've started doing is making videos of me playing the piano every Monday/Wednesday/Friday and sending it to my grandparents along with a little check-in. I'm also calling my parents and brother a lot, and doing Skype sessions with my friends.

I've followed CDC guidelines, social distancing and only going to the store for essentials. I have spent more time working on the truck and rollerblading and baking, all things that can be done at a safe distance from others. I've just been trying to stay busy, busy, busy without actually going anywhere.

\section{Lessons Learned}

While COVID-19 has affected medical education around the world, this experience demonstrated that a rapid transition to facilitate the continuation of learning was feasible. To our knowledge, this is also the first systematic evaluation of medical students' experiences in the immediate aftermath of changes forced on them academically and personally by COVID-19 and shed light on the unique, individual experience each student had.

Whereas some have called for large academic medical centers to set up centralized pandemic "response teams" [20], the transition to fully remote learning at ICOM happened immediately and successfully. This is not without precedent, as reports from Hong Kong amid the SARS outbreak in 2003 indicated a transition to remote learning did not significantly compromise education [21]. We believe that the key to ICOM's transition was a level of preparedness before COVID-19. An upfront interest in applying new technologies and openness to innovation had been integrated into the course at its start and throughout ICOM, a new medical school. ICOM's information technology department and curriculum coordinator facilitated faculty's quick adjustment to remote meetings, lecture capture, and assessment administration. Consistent with lessons learned from SARS in Ontario in 2003 [22], clear and frequent communication with students aided in students feeling supported.

Portrayals of medical students in the media [23, 24] and peer-reviewed literature $[11,12]$ often characterize them as uniformly eager to become involved in frontline efforts for COVID-19 with some even advocating for all incoming medical students to join the public health workforce [25]. Indeed, students were among the first to be called upon to fill in health worker gaps during the 1918 influenza pandemic [26] and many have contributed meaningfully during previous epidemics $[11,22]$. Consistent with the traditional altruism expected of medical professionals, we found that students were more concerned about how COVID-19 was affecting others rather than themselves.

Yet, we generally did not find that these pre-clinical students wanted to prioritize engaging in a battle with COVID-19: this was rarely mentioned in open-ended items asking students what was weighing on them most. While empiric data on medical student responses to COVID-19 are limited, one report indicated that clinical learners generally showed a mix of fear and obligation to join in the care of COVID-19 patients [9]. Other students have embraced "non-essential" status and raised concerns about risking one's health for the sake of learning [10]. Our data would support the approach taken by AAMC [27] and AACOM [28] which suggest offering opportunities for those who want to be involved, providing appropriate protections, and taking careful measures to avoid incentives that could coerce students to take unnecessary risks. 
Our study also provides insight into just how individualized each student's response to COVID-19 was. Medical schools generally should and do seek to enroll a diverse student body. At ICOM prior to social distancing, students clearly had varied ways of learning and living, yet also had access to a common physical learning environment and no restrictions in how they interacted inside and outside of class. Social distancing requirements limited students' options, and each clearly adjusted their learning and daily activities in different ways. More than ever, it mattered what the nature of a student's living space was, who was at home, who was not at home but at risk of becoming sick, and what medical condition a student or loved ones might have. Paradoxically, while the COVID-19 pandemic created a single shared experience that has become understood in an unprecedented manner worldwide, it has also given us far fewer shared experiences overall. The need to appreciate each student's context has always been important, but it appears more critical to actively seek to understand each aspect of a student's human experience in a time of crisis.

As students return to education as usual at ICOM, the faculty are applying what they have learned from a more intimate understanding of their students. Faculty have been specifically reminded that despite myriad educational innovations, their relationships with students as teacher remain a critical component to the educational process. Certainly, we cannot be sure whether the experience at ICOM represents those elsewhere. We hope that contextualizing students' academic and personal experiences in the immediate aftermath of the COVID-19 crisis in the USA will inform and encourage studies at other institutions and learning settings, and a realization that each student's experience must be appreciated when providing the support they need for academic and personal development.

Acknowledgments Dr. Slivkoff expresses deep gratitude to ICOM's Class of 2023 for being patient and mature during the transition to distance learning, and for their honesty in completing the survey.

\section{Compliance with Ethical Standards}

Ethics Approval This study was deemed exempt by the Boise State University Institutional Review Board (SB-IRB Notification of Exemption - 998-SB20-090).

Conflict of Interest Dr. Tackett receives salary support from Osmosis for research and scholarship. Ms. Johnson is an Osmosis employee and supported Dr. Slivkoff's use and evaluation of Osmosis in the ICOM curriculum.

\section{References}

1. Rose S. Medical student education in the time of COVID-19. JAMA. 2020;323(21):2131-2132.

2. Ahmed H, Allaf M, Elghazaly H. COVID-19 and medical education. Lancet Infect Dis. 2020;20(7):777-8.
3. Gill D, Whitehead C, Wondimagegn D. Challenges to medical education at a time of physical distancing. Lancet. 2020;396(10244):77-79.

4. Klasen JM, Vithyapathy A, Zante B, Burm S. "The storm has arrived": the impact of SARS-CoV-2 on medical students. Perspect Med Educ. 2020;9(3):181-5.

5. Hodges C, Moore S, Lockee B, Trust T, Bond A. The difference between emergency remote teaching and online learning. 2020. https://er.educause.edu/articles/2020/3/thedifference-between-emergency-remote-teaching-and-onlinelearning. Accessed 19 June 2020.

6. AACOM Updated message from AACOM regarding students returning to clinical activities. 2020. https://www.aacom.org/ news-and-events/news-detail/2020/05/05/updated-message-fromacom-regarding-students-returning-to-clinical-activities. Accessed 19 June 2020.

7. Whelan A, Prescott J, Young G, et al. 2020. Guidance on medical students' clinical participation: effective immediately. https://lcme. org/wp-content/uploads/filebase/March-17-2020-Guidance-onMediical-Students-Clinical-Participation.pdf. Accessed 19 June 2020.

8. The Coalition for Physician Accountability's Work Group on Medical Students in the Class of 2021. Final report and recommendations for medical education institutions of LCME-accredited, U.S. osteopathic, and non-U.S. medical school applicants. 2020. https://www.aamc.org/system/files/2020-05/covid19_Final Recommendations_05112020.pdf. Accessed 19 June 2020.

9. Gallagher TH, Schleyer AM. "We signed up for this!"- - student and trainee responses to the Covid-19 pandemic. N Engl J Med. 2020;382(25):e96.

10. Menon A, Klein EJ, Kollars K, Kleinhenz AL. Medical students are not essential workers: examining institutional responsibility during the COVID-19 pandemic. Acad Med. 2020;95(8):1149-1151.

11. Miller DG, Pierson L, Doernberg S. The role of medical students during the COVID-19 pandemic. Ann Intern Med. 2020;173(2): 145-146.

12. Soled D, Goel S, Barry D, Erfani P, Joseph N, Kochis M, et al. Medical student mobilization during a crisis: lessons from a COVID-19 medical student response team. Acad Med. 2020;95(9):1384-1387.

13. Theoret $\mathrm{C}$, Ming X. Our education, our concerns: medical student education impact due to COVID-19. Med Educ. 2020;54(7):591-2.

14. Cruess RL, Cruess SR, Boudreau JD, Snell L, Steinert Y. A schematic representation of the professional identity formation and socialization of medical students and residents: a guide for medical educators. Acad Med. 2015;90(6):718-25.

15. Chen DR, Priest KC, Batten JN, Fragoso LE, Reinfeld BI, Laitman BM. Student perspectives on the "step 1 climate" in preclinical medical education. Acad Med. 2019;94(3):302-4.

16. Cao W, Fang Z, Hou G, Han M, Xu X, Dong J, et al. The psychological impact of the COVID-19 epidemic on college students in China. Psych Res. 2020;287:112934.

17. Ullah R, Amin S. The psychological impact of COVID-19 on medical students. Psychiatry Res. 2020;1288:113020.

18. McGinty EE, Presskreischer R, Han H, Barry CL. Psychological distress and loneliness reported by US adults in 2018 and April 2020. JAMA. 2020;324(1):93-4.

19. Lichfield G. 2020. A guide to negotiating a covid "bubble" with other people. MIT Technology Review. https://www. technologyreview.com/2020/05/09/1001547/coronavirus-bubblepod-quaranteam-social-distancing-negotiation/. Accessed 19 June 2020.

20. Ashokka B, Ong SY, Tay KH, Loh NH, Gee CF, Samarasekera DD. Coordinated responses of academic medical centres to pandemics: sustaining medical education during COVID-19. Med Teach. 2020;13:1-10. 
21. Patil NG, Yan YC. SARS and its effect on medical education in Hong Kong. Med Educ. 2003;37(12):1127.

22. Rieder MJ, Salvadori M, Bannister S, Kenyon C. Collateral damage: the effect of SARS on medical education. Clin Teach. 2004;1(2):85-9.

23. Dwyer J. One final step for 52 medical students, eager to join the fight. 2020. https://www.nytimes.com/2020/04/06/nyregion/ coronavirus-medical-students-early-oath.html. Accessed 19 June 2020.

24. Krieger P, Goodnough A. Medical students, sidelined for now, find new ways to fight coronavirus. 2020. https://www.nytimes.com/ 2020/03/23/health/medical-students-coronavirus.html. Accessed 19 June 2020.

25. Bauchner H, Sharfstein J. A bold response to the COVID-19 pandemic: medical students, national service, and public health. JAMA. 2020;323(18):1790-1791.
26. Starr I. Influenza in 1918: recollections of the epidemic in Philadelphia. Ann Intern Med. 2006;145(2):138-40.

27. Whelan A, Prescott J, Young G, et al. Guidance on medical students' participation in direct patient contact activities. 2020. https:// www.aamc.org/system/files/2020-04/meded-April-14-Guidanceon-Medical-Students-Participation-in-Direct-Patient-ContactActivities.pdf. Accessed 19 June 2020.

28. AACOM Message on medical student participation in clinical activities. 2020. https://www.aacom.org/news-and-events/newsdetail/2020/03/17/aacom-message-on-medical-studentparticipation-in-clinical-activities. Accessed 19 June 2020.

Publisher's Note Springer Nature remains neutral with regard to jurisdictional claims in published maps and institutional affiliations. 